\title{
Potential of Mechanochemically Activated Sulfidic Mining Waste Rock for Alkali Activation
}

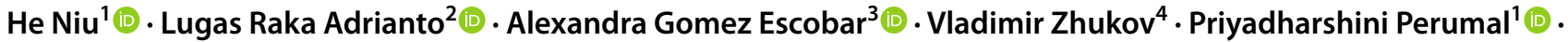 \\ Janne Kauppi ${ }^{4} \cdot$ Paivo Kinnunen $^{1}\left[\right.$ (I) Mirja Illikainen ${ }^{1}[0$
}

Received: 19 May 2021 / Accepted: 12 November 2021 / Published online: 1 December 2021

(c) The Author(s) 2021

\section{Abstract}

Sulfidic mining waste rock is a side stream from the mining industry with a potential environmental burden. Alkali activation is a promising method for transforming mining waste into construction materials. However, the low reactivity of minerals can be a sizeable challenge in alkali activation. In the present study, the reactivity of waste rock was enhanced by mechanochemical treatment with a LiCl-containing grinding aid. X-ray diffraction (XRD) and diffuse reflectance infrared Fourier transform (DRIFT) analysis were utilized to display the structural alteration of individual minerals. A schematic implication of the grinding mechanism of mica was provided according to the results of transmission electron microscopy (TEM) and scanning electron microscopy (SEM). The alkaline solubility displayed the enhanced chemical reactivity of the waste rock, in which $\mathrm{Si}$ and Al solubility increased by roughly 10 times and 40 times, respectively. The amorphization of aluminosilicate is achieved through chemical assisted mechanochemical activation. Sulfidic waste rock, as the sole precursor in alkali activation, achieved a 28-day compressive strength exceeding $10 \mathrm{MPa}$ under ambient curing conditions. The simulation of the upscaled grinding process was conducted via the HSC Chemistry ${ }^{\circledR}$ software with a life-cycle assessment. The results showed that mining waste rock can be a promising candidate for geopolymer production with a lower carbon footprint, compared to traditional Portland cement.

\section{Graphical Abstract}

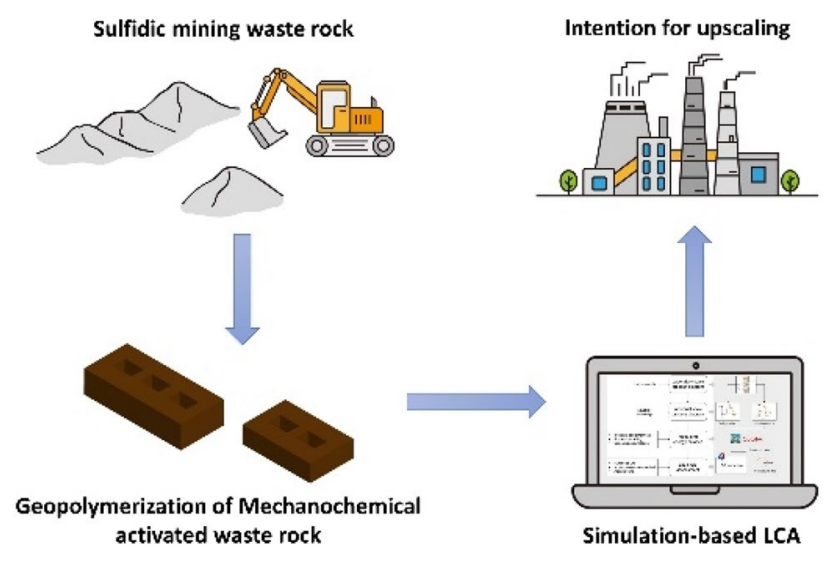

Keywords Mechanochemical activation $\cdot$ Sulfidic mining waste rock $\cdot$ Geopolymer $\cdot$ Valorization $\cdot$ Life-cycle assessment . HSC Chemistry $^{\circledR}$

The contributing editor for this article was João António Labrincha Batista.

Extended author information available on the last page of the article 


\section{Introduction}

Wastes from mining and mineral processing pose potential environmental and chronic burdens across the world. In North America, the stream of mining waste is as much as 10 times larger than the municipal solid waste per capita. According to a recent European statistics report, almost two thirds (65\%) of the total waste generated in the EU-27 in 2018 were composed of major mineral waste [1]. Waste rock is the material generated from excavation of ore, after which sections rich in ore are sent to further ore processing [2]. Mining waste rock is dumped near the mining site or stored in landfills, which can be a potential of pollutants. Leachable hazardous metals can dissolve into soil, and acid leachate can contaminate underground water through acid mine drainage (AMD). The utilization of mining wastes is concerning because it poses potential negative impacts on the landscape and local community. Mining waste rock has been used as a secondary raw material in building materials, such as aggregates and raw meals for Portland cement production [3]. However, construction materials produced solely with waste rock from sulfidic mining have hardly been studied.

Alkali activation is a promising method for transforming mining wastes into construction materials. Alkaliactivated materials (AAM) are produced from aluminosilicate rich precursors in alkaline conditions. Glukhovsky [4] proposed the conceptual model of the alkali activation of aluminosilicate materials in three stages: (1) dissolution of aluminate and silicate, (2) reorientation and reorganization, and (3) polymerization and hardening. A subgroup of alkali-activated materials is geopolymers, which consist of $\mathrm{SiO}_{4} \mathrm{AlO}_{4}$ tetrahedra linked with sharing oxygens, while positively charged ions balance the negative charge of $\mathrm{Al}^{3+}$ in fourfold coordination [5]. The general precursors for geopolymers are metakaolin, fly ash, and low-Ca slags, which are chemically reactive. Crystalline materials such as clay minerals, mine tailings, and waste rock cannot be directly used as precursors due to their low chemical reactivity.

As mentioned previously, mining waste rocks are crystalline materials that cannot be directly utilized as precursors for alkali activation. Multiples attempts have been made to increase the reactivity of the mineral precursors. Torgal et al. [6] conducted heat treatment on mud waste containing muscovite and found that $11.5 \%$ of crystalline muscovite survived after calcination at $950{ }^{\circ} \mathrm{C}$ for $2 \mathrm{~h}$. Another study on the activation of raw clay via a mechanochemical process showed that a 25 -min ball milling of muscovite-containing clay minerals under optimized grinding parameters can sufficiently disrupt the crystalline structure [7]. However, it should be noted that those clay minerals were originally from Swedish regions, which are known for having "quick clay" that has been skeleton collapsed under high crust strain [8]. This means that the raw materials can be, to some extent, amorphous before mechanochemical activation. Moukannaa et al. [9] prepared a mortar by fusing phosphate mine tailings with $10 \% \mathrm{NaOH}$ at $550{ }^{\circ} \mathrm{C}$. They found that the compressive strength was $40 \mathrm{MPa}$ after 28 days after the synergy with metakaolin. The aforementioned pre-treatments are relatively time and energy consuming. Although mechanochemical activation by ball milling was successfully implemented on "quick clay," it is unlikely to disrupt a highly crystalline structure within several minutes. Yao et al. [10] ball milled the highly crystalline muscovite at $500 \mathrm{rpm}$ for $200 \mathrm{~min}$; afterwards, its enhanced pozzolanic reactivity was evaluated by substituting $30 \%$ cement in mortar without detriment to compressive strength. However, waste rock is a more complex mixture in which the individual minerals can interact with each other. Consequently, it is important to investigate the amorphization of mica in a complicated system. In the current paper, sulfidic waste rock, resulting from sulfidic ores, was investigated.

Lithium-based grinding aids have been found to display promising results in enhancing the disruption of the micaceous structure (aluminosilicate), thereby improving its chemical reactivity before alkali activation. For example, disruption of the muscovite mica structure [11] has been achieved by immersing mica in a $\mathrm{LiCl}$ solution for $24 \mathrm{~h}$ before wet-ball milling. Since the late 1990s, chemically assisted dry comminution (CADC) has been used as a processing method for improving the surface area of solid materials. The application of CADC on sericite in the presence of lithium nitride accompanied by ion exchange with potassium significantly increases the specific surface area of mica [12]. Solvent-assisted dry grinding is a simpler pathway, in which only a few drops of grinding aid are added without using a large volume of the chemicals involved in both CADC and wet-ball mills.

Therefore, this work aims to investigate the effect of a small amount $(0.2 \mathrm{wt} \%)$ of grinding aid on mica-containing waste rocks and how it affects the application of mechanochemically activated waste rock as the sole precursor for geopolymerization.

To fully investigate the potential of using sulfidic waste rocks as secondary raw materials for geopolymer production, a simulation-based method was applied by a dynamic process simulator (HSC Chemistry ${ }^{\circledR}$ developed by Metso Outotec) [13]. A perspective life-cycle assessment (LCA) was conducted for geopolymer production based on simulated upscaling strategies. A process model based on case studies, such as ore processing has been previously investigated [14-18]; however, the simulation of geopolymer binder production has barely been studied before. 


\section{Materials and Methods}

\section{Waste Rock from Neves Corvo (SOMINCOR by Lundin Mining)}

Neves Corvo is an underground high-grade $\mathrm{Cu}-(\mathrm{Sn})-\mathrm{Zn}$ mine located in the Portuguese sector of the Iberian Pyrite Belt (IPB) in the district of Beja, $220 \mathrm{~km}$ southeast of Lisbon (Fig. 1). Copper production started in 1989, followed by tin production between 1990 and 2001, then by zinc/ lead production in 2006 [19]. At present, Neves Corvo's production capacity reaches 2.6 million tons per annum (mtpa) of copper and $1.1 \mathrm{mtpa}$ of zinc and lead combined [20].

Mining activity and the production of base metal concentrates in Neves Corvo generates two different residues: (i) waste rock, the hosting rock extracted and crushed during mining operations, and (ii) tailings, the final residues from the two processing plants. The waste rock consists of variably mineralized felsic volcanic rocks and black schist with disseminated sulfides (mostly composed of muscovite, plagioclase, quartz, chlorite, pyrite, \pm chalcopyrite, \pm sphalerite, \pm gypsum \pm carbonates, other oxides, and silicates). The tailings are essentially composed of pyrite ( 80 to $90 \mathrm{wt} \%$ ), sphalerite, chalcopyrite, galena, and gangue minerals Over a 9-year period from 2010 to 2019, the Neves Corvo operation accumulated 7.3 Mt of waste rock stored at the Cerro do Lobo Tailings Management Facility (TMF) and disposed of $17 \mathrm{Mt}$ of thickened tailings, while 3.1 million tons of oxidized waste rock had been stored in a temporary stockpile by the end of 2019 . Neves Corvo mine had implemented a series of geochemical and geotechnical strategies where risks associated with

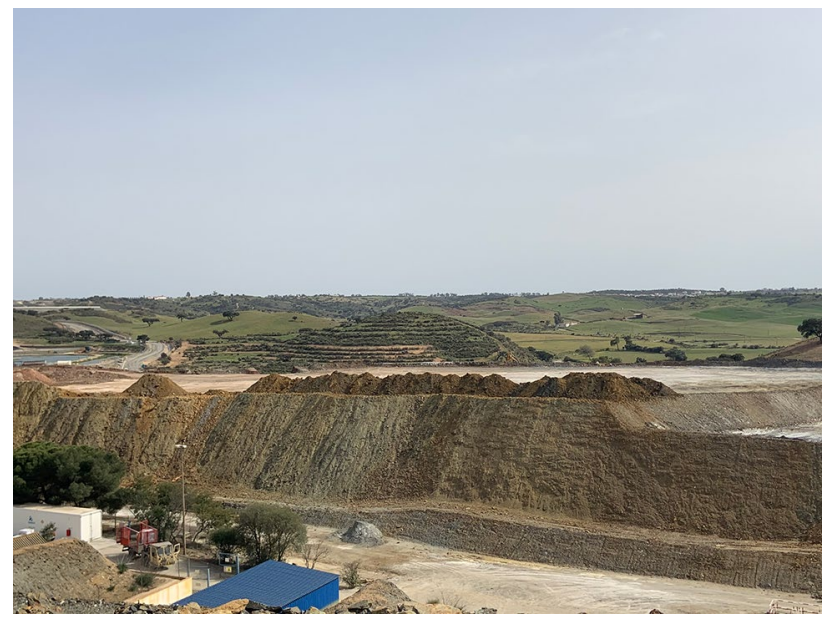

Fig. 1 General view of waste rock stockpiles at the Neves Corvo mine (Portugal) potential acid mine drainage (AMD) are kept controlled and stable at the stockpile and the tailings dam, reducing environmental impacts [21].

\section{Materials Preparation}

The fresh sulfidic mining waste rock was jaw crushed with a Wedag jaw crusher and double roller crushed using a Mesto Minerals Marcy roller crusher until a particle size lower than $1 \mathrm{~mm}$ was achieved for the preparation for the subsequent mechanochemical activation and synthesis of alkali-activated materials. Lithium chloride (BioXtra, $\geq 99.0 \%)$ and methanol $(99.9 \%)$ were purchased from Sigma-Aldrich. Prior to the mechanochemical activation, the waste rocks were ground using a vibratory disk mill (Retsch RS 100) for $1 \mathrm{~min}$ at $1500 \mathrm{rpm}$ (dubbed as G1). Mechanochemically activated waste rock was done via grinding with the addition of $0.2 \mathrm{wt} \%$ grinding aid ( $40 \mathrm{wt} \%$ $\mathrm{LiCl}$ methanol solution) for up to 8 and $16 \mathrm{~min}$ (dubbed as $\mathrm{G} 8 \mathrm{LiCl}$ and $\mathrm{G} 16 \mathrm{LiCl}$, respectively). The control group was subjected to 8 - and 16-min grinding with $0.2 \mathrm{wt} \%$ grinding aids (isopropanol; $\geq 99.7 \%$; VWR Chemicals), dubbed as G8 and G16, respectively. The chemical composition of waste rock is given in Table 1, and the sample coding is presented in Table 2.

Table 1 Chemical composition of waste rock

\begin{tabular}{lr}
\hline Main component & $(\mathrm{Wt} \%)$ \\
\hline $\mathrm{SiO}_{2}$ & 52.31 \\
$\mathrm{Al}_{2} \mathrm{O}_{3}$ & 12.15 \\
$\mathrm{CaO}$ & 0.56 \\
$\mathrm{MgO}$ & 1.98 \\
$\mathrm{~K}_{2} \mathrm{O}$ & 1.49 \\
$\mathrm{Fe}_{2} \mathrm{O}_{3}$ & 16.69 \\
$\mathrm{SO}_{3}$ & 12.34 \\
$\mathrm{TiO}_{2}$ & 0.56 \\
$\mathrm{MnO}$ & 0.13 \\
L.O.I & 9.7 \\
\hline
\end{tabular}

Table 2 Sample coding

\begin{tabular}{ll}
\hline Sample coding & Description \\
\hline G1 & 1-min grinding waste rock \\
G8 & 8-min grinding waste rock \\
G16 & 16-min grinding waste rock \\
G8LiCl & 8-min grinding waste rock with $\mathrm{LiCl}$ \\
G16LiCl & 16-min grinding waste rock with $\mathrm{LiCl}$ \\
IPG16 & Geopolymer produced from $\mathrm{G} 16$ \\
IPG16LiCl & Geopolymer produced from $\mathrm{G} 16 \mathrm{LiCl}$ \\
\hline
\end{tabular}


Table 3 Mix design of geopolymer

\begin{tabular}{lllll}
\hline $\begin{array}{l}\text { Sample } \\
\text { name }\end{array}$ & $\begin{array}{l}\text { Waste rock } \\
(\mathrm{wt} \%)\end{array}$ & $\begin{array}{l}\mathrm{NaOH} \\
(\mathrm{wt} \%)\end{array}$ & $\begin{array}{l}\text { Sodium } \\
\text { silicate } \\
\text { solution } \\
(\mathrm{wt} \%)\end{array}$ & $\begin{array}{l}\text { Water/binder } \\
\text { ratio }\end{array}$ \\
\hline IPG16LiCl & 73.15 & 1.74 & 25.11 & 0.2 \\
\hline
\end{tabular}

\section{Synthesis of Waste Rock-Based Geopolymer}

The mix design is given in Table 3. The alkali activator (molar ratio of $\mathrm{SiO}_{2} / \mathrm{Na}_{2} \mathrm{O}=1.33$ ) was prepared by adding dry sodium hydroxide pellets (VWR Chemicals, > 97\%) to sodium silicate solution (VWR Chemicals, $\mathrm{SiO}_{2}: 26.5 \%$, $\mathrm{Na}_{2} \mathrm{O}: 8 \%, \mathrm{H}_{2} \mathrm{O}: 65.5 \%$ ). No extra water was added. The alkali-activated waste rock was produced by mixing mechanochemically activated waste rock and an alkali activator using a shear mixer (IKA ${ }^{\circledR}$ WERKE) for $3 \mathrm{~min}$ at $700 \mathrm{rpm}$. Thereafter, the paste was molded in the Teflon molds with dimensions of $2 \mathrm{~cm} \times 2 \mathrm{~cm} \times 8 \mathrm{~cm}$. A vibrating machine (Vortex-Genie 2, Prolab Oy) was used to remove all air bubbles. The sample was demolded after curing under ambient conditions for $24 \mathrm{~h}$ and then continuously cured in a plastic bag until the test. This was nominated as IPG16LiClt, where IP and t represent the geopolymer and the curing time, respectively. In this work, the precursor from mining waste rock was relatively rich in aluminosilicates.

\section{Characterization}

The chemical composition of mining waste rock was determined using a PANalytical AXiosmAX XRF spectrometer with a rhodium tube, which has a maximum power rate of $4 \mathrm{~kW}$. The particle-size distribution (PSD) and Brunauer-Emmett-Teller (BET) surface area were determined using a laser diffraction particle-size analyzer (LS 13320, Beckman Coulter, Inc., Brea, CA, USA) and ASAP 2000 Micrometrics, respectively. XRD analysis was done using a Rigaku SmartLab $4.5 \mathrm{~kW}$, with the equipment parameters of Co source ( $40 \mathrm{kV}$ and $135 \mathrm{~mA}) K_{\alpha}\left(K_{\alpha 1}=1.78892 \AA\right.$; $\left.K_{\alpha 2}=1.79278 \AA ; K_{\alpha 1} / K_{\alpha 2}=0.5\right)$, scan rate of $3 \% \mathrm{~min}$, and $0.02 \%$ step. Quantitative analysis was performed by using the PDXL2 Software Suite with integrated access to the PDF-4 (2019) database and $10 \mathrm{wt} \%$ rutile (powder; $<5 \mu \mathrm{m} ; \geq 99.9 \%$ trace; metal basis) as the internal standard. The alkaline solubility of the ground powder was evaluated by mixing with a $6 \mathrm{M} \mathrm{NaOH}$ solution in polypropylene bottles at a liquid/ solid mass ratio of 200/1. A horizontal shaking table (IKA
KS 260 orbital shaker) was utilized at Mot $=150 / \mathrm{min}$ for $24 \mathrm{~h}$ in a moderate environment, which was set at $23 \pm 0.5^{\circ} \mathrm{C}$ with $50 \%$ humidity. Thereafter, the resulting specimens were filtered by using a $0.2 \mu \mathrm{m}$ filter paper, and the filtrate was acidified with $6 \mathrm{M} \mathrm{HNO}_{3}$ to a $\mathrm{pH}$ lower than 1 . The concentration of $\mathrm{Si}$ and $\mathrm{Al}$ elements was measured using the inductively coupled plasma-optical emission spectroscopy (ICP-OES) technique. A vibrational analysis of waste rocks was performed by using diffuse reflectance infrared Fourier transform (DRIFT). The spectra were collected via a Bruker Vertex 80v spectrometer (USA) with a range of $400-4000 \mathrm{~cm}^{-1}$, and 40 scans were taken at a resolution of $1 \mathrm{~cm}^{-1}$ for each sample. The morphology of the specimen was characterized using Zeiss ULTRA plus (scanning electron microscopy) SEM with an acceleration voltage of $5 \mathrm{kV}$. An EDS (Energy-Dispersive X-Ray Spectroscopy) analysis was conducted with an acceleration voltage of $15 \mathrm{kV}$ and a beam current of $120 \times 10^{-8}$ A. The polished cross section of the geopolymer sample was subjected to a 50-point analysis under the magnification of $\times 3000$ and a working distance of 6 to $8 \mathrm{~mm}$. The morphological features of ground waste rock samples were measured by a transmission electron microscope (TEM) (JEOL JEM-2200FS, Japan). The preparation of the samples was performed by dispersing a small amount of powder (about $0.05 \mathrm{~g}$ ) in high-purity ethanol $(5 \mathrm{ml})$; the sample was then vibrated in a sonicated bath for $5 \mathrm{~min}$. A drop of diluted powder suspension was placed onto the standard $\mathrm{Cu}$ TEM grid covered with a perforated lacey carbon film. The standard conditions of $200 \mathrm{kV}$ were used during the TEM analysis. Unconfined compressive strength was assessed using a Zwick Roell 100kN machine with a loading force of $2.4 \mathrm{kN} / \mathrm{s}$ until failure.

\section{Life-Cycle Assessment (LCA)}

\section{System Definition and Functional Unit}

LCA is a standardized method for assessing the potential environmental impacts of a product or system. The goal of this study is to evaluate the environmental performance of alkali-activated binder from waste rock in comparison to that of ordinary Portland cement (OPC). Thus, the LCA was calculated by defining the functional unit as the production of " $1 \mathrm{~kg}$ of binder material". To make the analysis comparable to that of standard Portland cement, a multiplier factor was introduced as a substitution ratio [22, 23], which is formulated as follows:

Substitution ratio $=\frac{\text { 28-day compressive strength }(\mathrm{MPa})}{28 \text {-day compressive strength }(\mathrm{MPa}) \text { of base case material }}$. 
When comparing the LCA results of the developed geopolymer binder and Portland cements, the impacts of the geopolymer were divided by the substitution ratio above, (i.e., 0.26). All the environmental impacts in this study were evaluated using the following six midpoint methods: (1) global warming potential (IPCC 2013), (2) cumulative energy demand, non-renewable (CED), (3) ReCipe water depletion, (4) ReCipe particulate matter formation, (5) CML 2002 resource depletion, (6) CML 2002 acidification potential [24], and (7) ReCipe 2016 Endpoint (H) to account for overall impacts across categories [22].

\section{Data Collection and Life-Cycle Inventory (LCI) Calculations}

The first step comprises a conversion of lab protocols into a lab-scale process diagram (Fig. 2). Central to this step are minerals and particle-size characterizations, i.e., mineralogy and grain sizes (refer to electronic supplementary materials, Supplementary Fig. S1, Tables S1, S2), and the results are obtained from experimental steps in "Characterization" section. The information was used as necessary input data in the subsequent step, mass, and energy balance computer simulation, within HSC Sim 10 [25].

In the second step, various possible large-scale process flow diagrams were accounted by building three configurations for the mechanochemical activation of waste rocks by translating lab-scale processes to their equivalent industrial equipment (see Supplementary Table S3, Figs. S2-S4). These three configurations represent expert and technology experts' knowledge in the upscaling aspects of this study. When looking for equivalent industrial-scale processes, the equipment was chosen based on the functionalities and performances that align with actual requirements. For example, the lab-scale jaw crusher, double-roller crusher, sieving equipment, and vibratory disk mill are used as the main comminution equipment on a large scale. Specifically, for

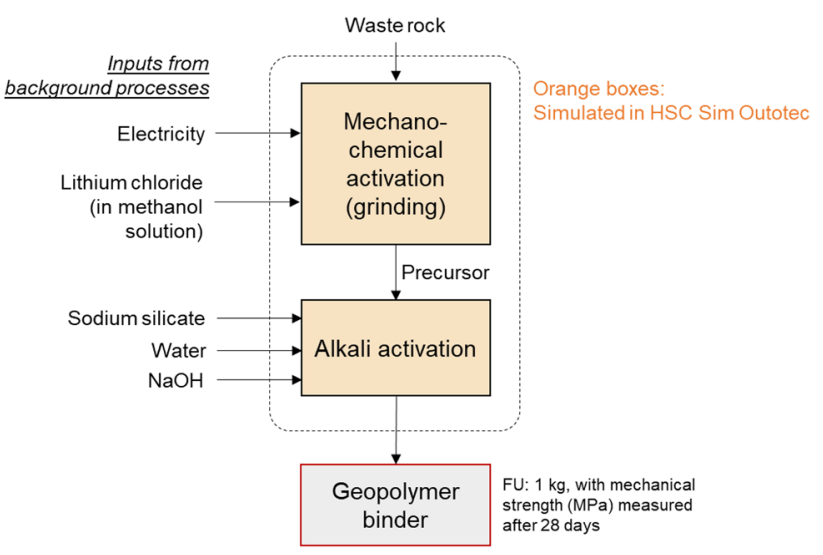

Fig. 2 Lab-scale process flow diagram of waste rock mechanochemical activation (Color figure online) geopolymer binder making, the mix design ratio, as shown in Table 3, is kept the same for both lab-scale and all largescale configurations.

In the third step, model configurations were constructed in HSC Sim 10 by providing input data from experiments and external resources, i.e., industrial data and expert opinions (see Supplementary Section B for design considerations). The established flowsheet models embrace a range of controls, such as working parameters, residence time, and feed properties [26]. It is notable that the modularity of unit processes in HSC Sim 10 allows for parameterizations in the models. In combination, the previous three steps are completed to generate the mass and energy balance that will be used for the life-cycle inventory of the study. The generated inventories are then transferred to the LCA modeling software for calculating the environmental impacts using the life-cycle impact assessment methods chosen in the previous section. In this study, Activity Browser software was used to run the LCA modeling [27]. The background data, such as European electricity mix and chemicals usage in the technosphere, were taken directly from the well-established LCA database Ecoinvent 3.7 [28], while all foreground data were obtained from the results of flowsheet simulations. It was assumed that the production facilities were near the waste rock storage facility; hence, the transporting efforts were excluded. The overall LCA procedure and the process for conducting the analysis for comparative purposes are shown in Fig. 3.

\section{Results and Discussion}

\section{PSD and BET}

The cumulative particle-size distribution curve displays the difference between G1, G16, and G16LiCl (Fig. 4). Grinding without the aid of chemicals hardly increases the BET surface area and results in only a small decrease in particle size. Lithium chloride can efficiently enhance mechanochemical activation, whereby almost $98 \%$ of particles are smaller than $20 \mu \mathrm{m}$ and $50 \%$ smaller than $3 \mu \mathrm{m}$. The corresponding BET surface area increases from 2.10 to $18.01 \mathrm{~m}^{2} / \mathrm{g}$, whereas the BET surface area of the samples milled without grinding aid only increases to $3.81 \mathrm{~m}^{2} / \mathrm{g}$. The effect of mechanochemical activation also results in the amorphization of minerals in the waste rock. The grinding aid has a significant influence on aluminosilicate minerals, such as muscovite and clinochlore. On the contrary, stable minerals, such as quartz and pyrite, are kept intact during mechanochemical activation. The morphology depicts samples with markedly different features. G8 and G16 display a pristine muscovite laminar structure, while $\mathrm{G} 8 \mathrm{LiCl}$ and $\mathrm{G} 16 \mathrm{LiCl}$ have irregularly shaped particles (Fig. 5). 
Fig. 3 Steps to perform lifecycle assessment of mechanochemically activated precursor

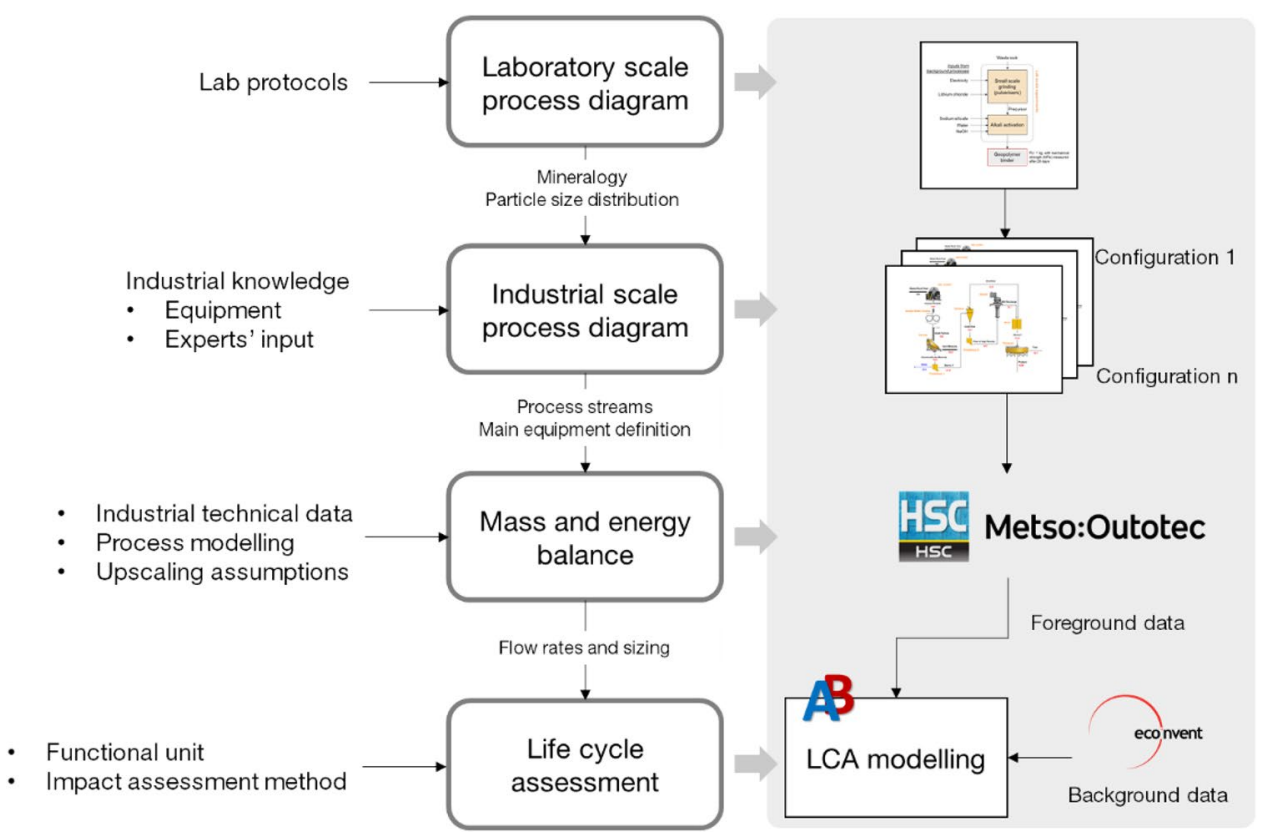

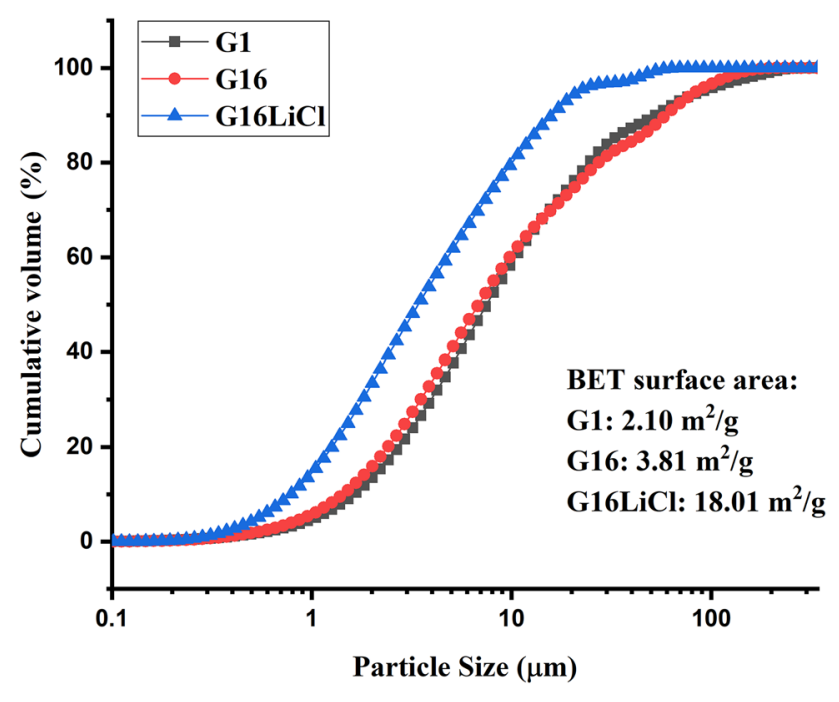

Fig. 4 Particle-size distribution of ground samples

\section{XRD and DRIFT}

The XRD patterns were identified using PDXL2 software (Fig. 6a). These phases include quartz (ICDD; PDF 04-0147569), pyrite (ICDD; PDF 04-004-6511), muscovite (ICDD; PDF 04-016-3068), clinochlore (ICDD; PDF 04-022-2452), and gypsum (ICDD; PDF 04-010-9409) with internal standard rutile (ICDD; PDF 04-008-7847). The structure of layered aluminosilicate (muscovite and clinochlore) is considerably disrupted after a 16-min grinding with $\mathrm{LiCl}$, while ground aluminosilicates without $\mathrm{LiCl}$ remain intact, comparable to the untreated waste rock. The XRD pattern of $\mathrm{G} 16 \mathrm{LiCl}$ shows line broadening, and the peaks of layered aluminosilicate almost disappeared in comparison with G16 and untreated waste rock. The results of quantitative XRD analysis further confirm the diffraction line broadening and decrease in intensity in XRD patterns (Fig. 7). The quantitative analysis errors may result from the heterogeneity of waste rock during crushing and grinding. The DRIFT patterns reflect the structural alteration of aluminosilicate minerals in Fig. 6b. The $\mathrm{Si}-\mathrm{O}$ stretching band at $1062 \mathrm{~cm}^{-1}$ and $\mathrm{Si}-\mathrm{O}$ bending at $520 \mathrm{~cm}^{-1}$ disappear, indicating the collapse of silicate structure. In addition, a splitting band appears at $1465 \mathrm{~cm}^{-1}$ and $1277 \mathrm{~cm}^{-1}$. The heavy distortion during grinding results in a misfit between octahedral and tetrahedral sheets, thereby resulting in tetrahedral rotation [29]. The bands noticeable at $1670 \mathrm{~cm}^{-1}$ and $1610 \mathrm{~cm}^{-1}$ are assigned to molecular water bending modes, while the bands between 2200 and $1700 \mathrm{~cm}^{-1}$ correspond to the harmonic combination of bands between 400 and $1000 \mathrm{~cm}^{-1}$ [30]. For clinochlore, the $\mathrm{OH}$ liberation band around 600 to $800 \mathrm{~cm}^{-1}$ remains for all ground samples, as is the case for heat-treated/mechanically treated clinochlore [31-33]. Nevertheless, the decreased intensity also occurs in clinochlore: the $3550 \mathrm{~cm}^{-1}$ band practically vanishes after grinding with $\mathrm{LiCl}$ grinding aid. The stretching vibration of absorbed water molecules is ascribed to a broad band at around $3430 \mathrm{~cm}^{-1}$. There was no significant difference seen when treated with 16-min grinding. However, the broad band at $933 \mathrm{~cm}^{-1}$ for Al-OH disappears, a result that differs from the heat-treated case [34]. The band at $3627 \mathrm{~cm}^{-1}$ is assigned to the $\mathrm{OH}$ stretching absorption of muscovite, during which the intensity decreases [35]. In conclusion, dehydroxylation occurred during the mechanochemical process, resulting in a change 
Fig. 5 Morphology of a G8, b G16, c G8LiCl, and d G16LiCl
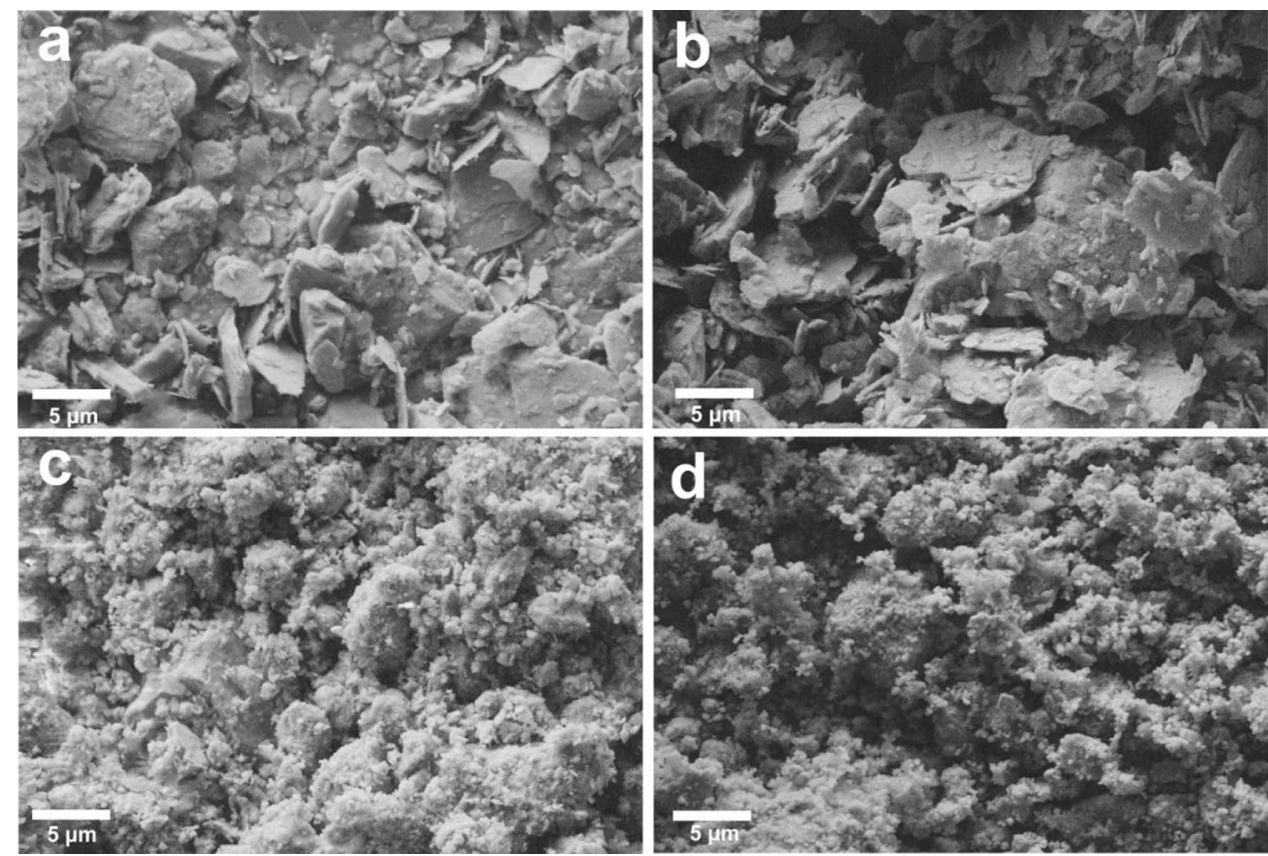
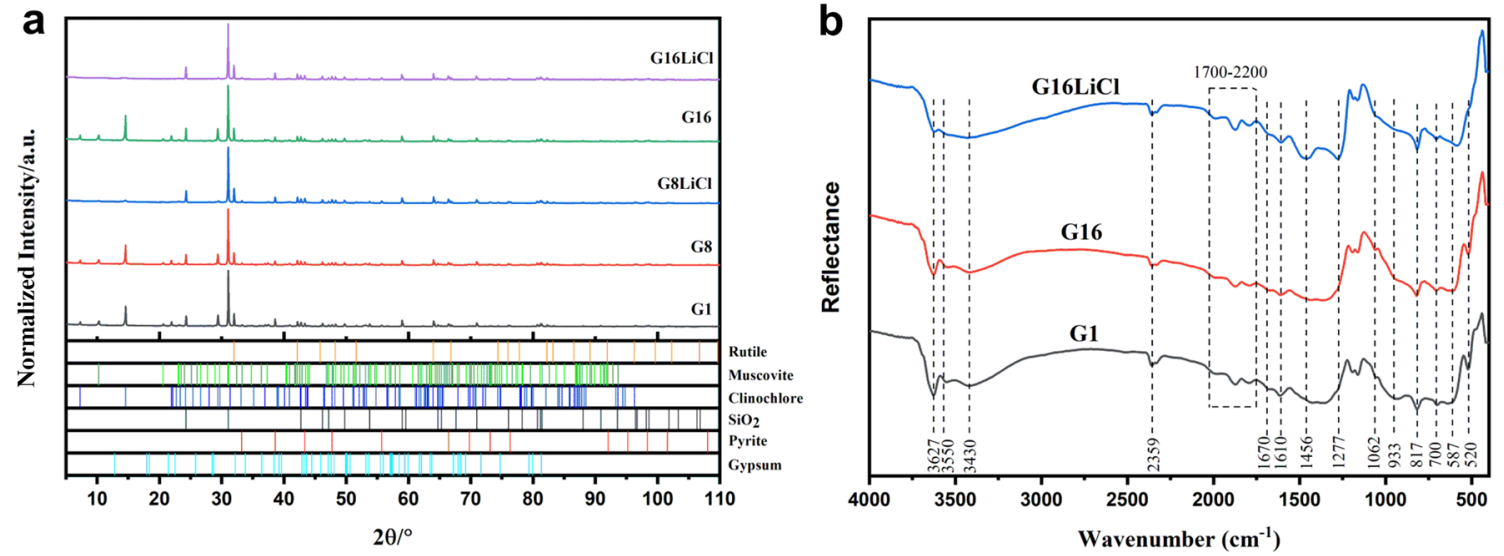

Fig. 6 a XRD patterns and b DRIFT spectra of ground samples

in aluminum coordination for further geopolymerization with silicate species.

In muscovite, $\mathrm{KAl}_{2}\left[\mathrm{AlSi}_{3} \mathrm{O}_{10}(\mathrm{OH})_{2}\right]$, a quarter of $\mathrm{Si}^{4+}$ is substituted by $\mathrm{Al}^{3+}$, leading to a negative unit charge, which is filled in by a $\mathrm{K}^{+}$. The mineral is also known as dioctahedral mica since $\mathrm{Al}^{3+}$ occupies the M2 octahedral sites, while the M1 octahedral sites are vacant [36]. There are two possible ways for lithium ions to influence the amorphization of the waste rocks: (1) $\mathrm{Li}^{+}$shows a tendency to enter the vacant position in the dioctahedral layer of mica, thereby changing its charge balance and expelling $\mathrm{K}^{+}$from the interlayer position [37]; (2) $\mathrm{Li}^{+}$has the smallest cation size and highest electronegativity out of all alkali metals, causing it to enter into the interlayer and push $\mathrm{K}^{+}$out. Figure 8 shows a schematic diagram of the function of the lithium cation during grinding. High-energy grinding impacts the structure of mica not only through delamination but also by the dislocation of the layered structure of mica upon incorporation of the lithium cation. Furthermore, only a small amount (0.2 wt $\%$ ) of the grinding aid can affect the layered structure.

\section{TEM}

TEM is a vital tool for investigating detailed features of crystalline and amorphous phases. As reported previously, mica is sensitive to electron beams which means it can decompose under electron radiation [38]. Therefore, the radiation damage rate (RDR) should be considered during TEM 


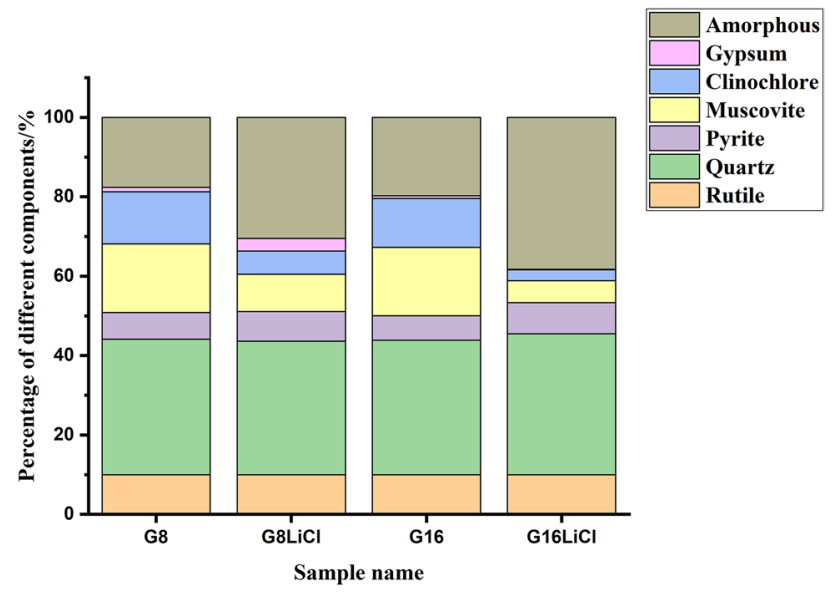

Fig.7 Quantitative analysis of ground samples

measurement. The diffraction pattern is obtained within $90 \mathrm{~s}$ because the RDR of muscovite is classified between medium and fast. A high-resolution transmission electron microscope (HRTEM) can reflect the mineral structure change on a nanoscale and disordered mica can be found in a sample ground for $16 \mathrm{~min}$ (Fig. 9). The figure also displays associated selected area diffraction (SAD) patterns from both $\mathrm{G} 8 \mathrm{LiCl}$ and $\mathrm{G} 16 \mathrm{LiCl}$, and $\mathrm{G} 16 \mathrm{LiCl}$ explicitly shows SAD patterns with diffuse rings from the completely amorphous region at b's center. A combined diffused ring with a matrix spot pattern appears in $\mathrm{G} 8 \mathrm{LiCl}$, and this indicates the intermediate transmission from the crystalline phase to the amorphous phase. The lattice parameters of both samples were determined by XRD diffraction. Results indicate that a considerable change occurs in the $\mathrm{c}$ axis, that is, probably due to the compression along the (001) cleavage plane, leading to structural distortion [39].

Arrays of the (001) plane have rotated in the boundary across for the diffraction pattern of $\mathrm{G} 8 \mathrm{LiCl}$, the misorientation of (001) becomes slightly rotated, meaning that the complex interleaving of the boundary has occurred, as reported in the literature [38]. This result is consistent with the XRD analysis results indicating that the (001) reflection becomes a hump after 8-min grinding. The amorphous halo of $\mathrm{G} 16 \mathrm{LiCl}$ indicates that there is only a partial orientation in the muscovite structure, i.e., it partially loses crystallinity after 16 min of intense grinding with $\mathrm{LiCl}$ media. In addition, a delaminated and irregular particle can be seen in the HRTEM (Fig. 9b).

\section{Alkali Activation Potential}

The alkaline dissolution results show enhanced aluminum and silicon dissolution (Fig. 10a). Since Si is located in a stable $\mathrm{Si}-\mathrm{O}$ bonding environment within quartz and layered aluminosilicates, a lower enhancement of Si solubility can be seen (Fig. 10a). Al solubility experiences a small increase after grinding without $\mathrm{LiCl}$; however, after grinding with $\mathrm{LiCl}$ for $16 \mathrm{~min}, \mathrm{Al}$ solubility shows up to a 40 -fold increase. The XRD reflection patterns and Rietveld refinement of ground samples after solubility tests are shown in Supplementary Figs. S5-S8. There are few changes seen for both G1 and G16, while G16LiCl exhibits a considerable amount of amorphous phase (43.1\%). Si solubility also increases tenfold for $\mathrm{G} 16 \mathrm{LiCl}$, and dissolved silicate units come from layered aluminosilicates, as quartz is chemically inert. The morphology of samples after the dissolution test is shown in Supplementary Figs. S9 and S10. G16 retains its regular particle shape, while $\mathrm{G} 16 \mathrm{LiCl}$ exhibits an amorphous gellike structure after the alkaline dissolution test. G16 particles retain their regular shape with clear grain boundaries, and the major elements ( $\mathrm{Al}, \mathrm{Si}$, and $\mathrm{K}$ ) are homogenously distributed without conspicuous dissolution. In contrast, higher $\mathrm{Al}$ and $\mathrm{Si}$ dissolution occurs for $\mathrm{G} 16 \mathrm{LiCl}$ particles during the dissolution test, thereby indicating an amorphous

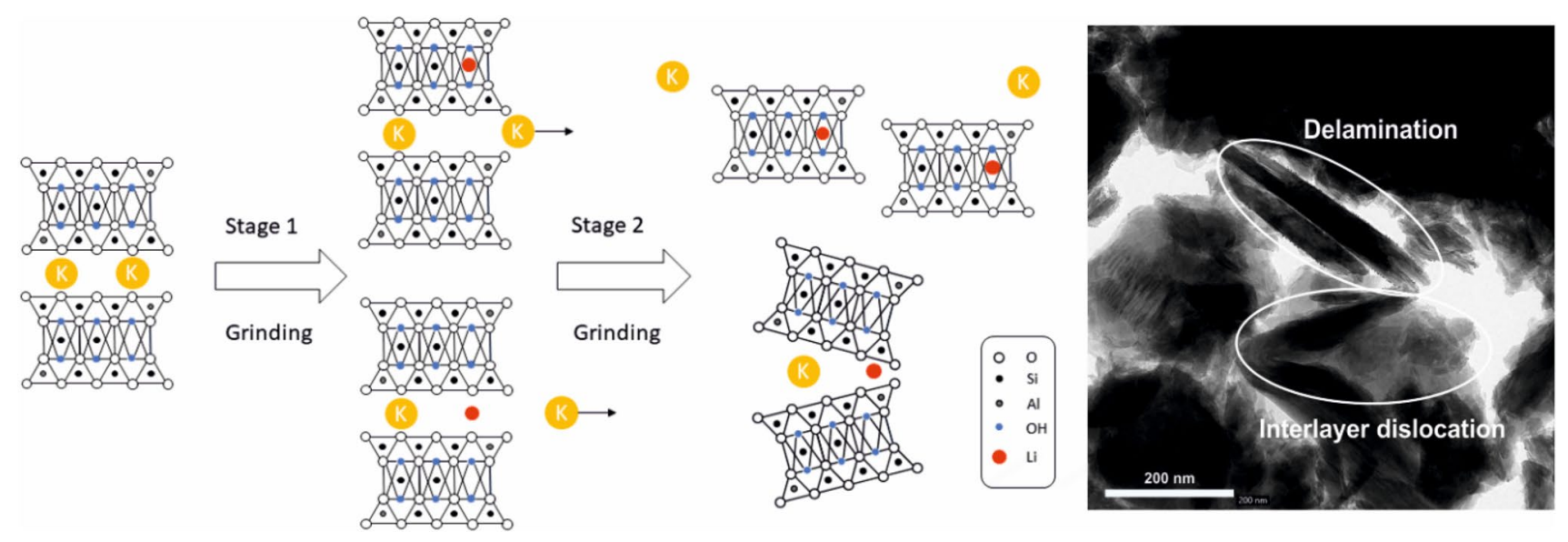

Fig. 8 Schematic implication of grinding mechanism of mica 
Fig. 9 TEM analysis of G8LiCl (a, c) and $\mathrm{G} 16 \mathrm{LiCl}(\mathbf{b}, \mathbf{d})$. Lattice parameters of G8LiCl: a(ang.): 5.19 (0.0020ESD), b(ang.): 9.00 (0.0042ESD), c(ang.): 20.18 (0.0077ESD); Lattice parameters of G16LiCl: a(ang.): 5.21 (0.0001), b(ang.): 8.98 (0.0004ESD), $\mathbf{c}$ (ang.): 20.26 (0.0014ESD). The evaluation value (Rwp) was promised to be lower than 2 after refinement
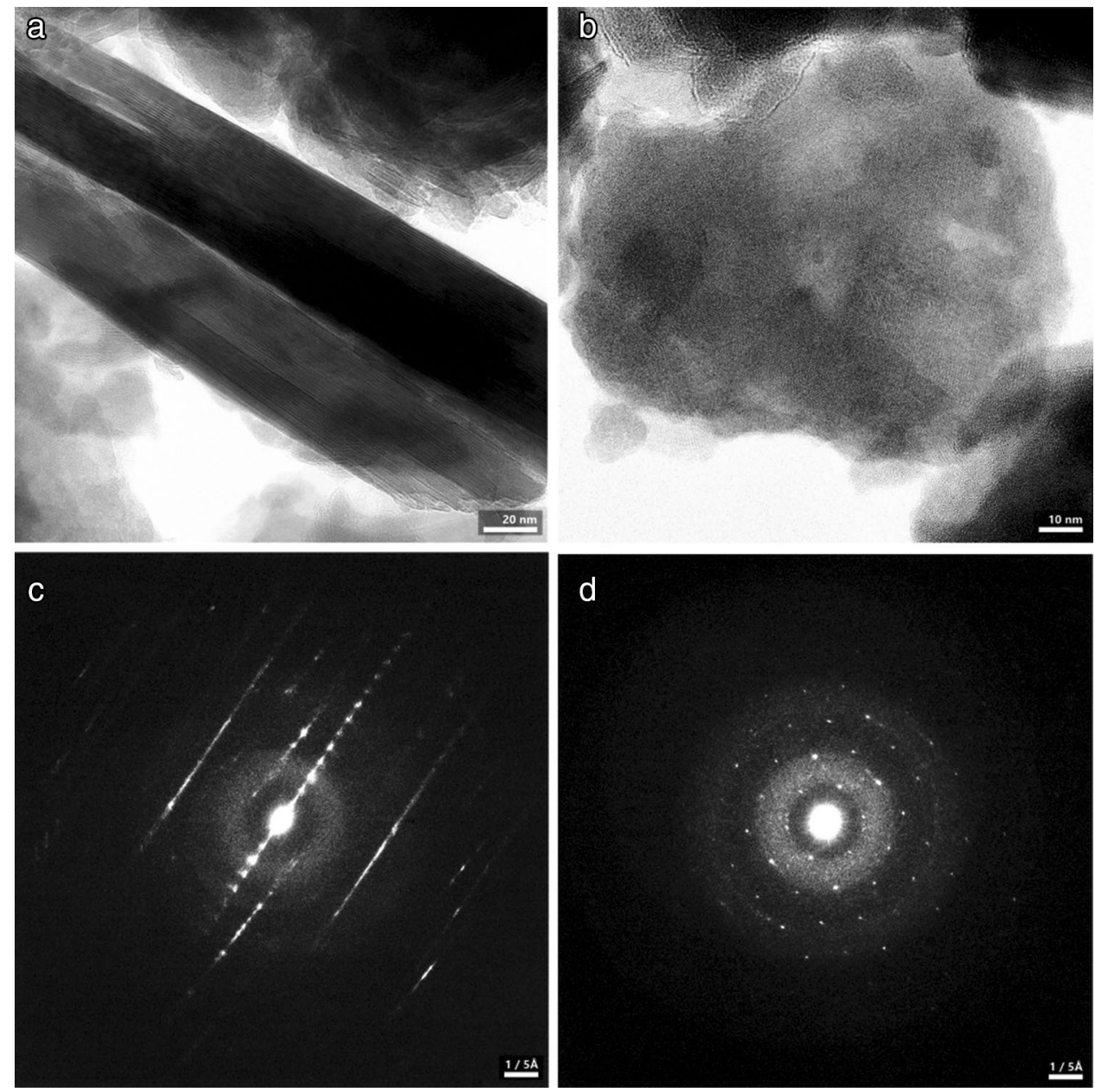
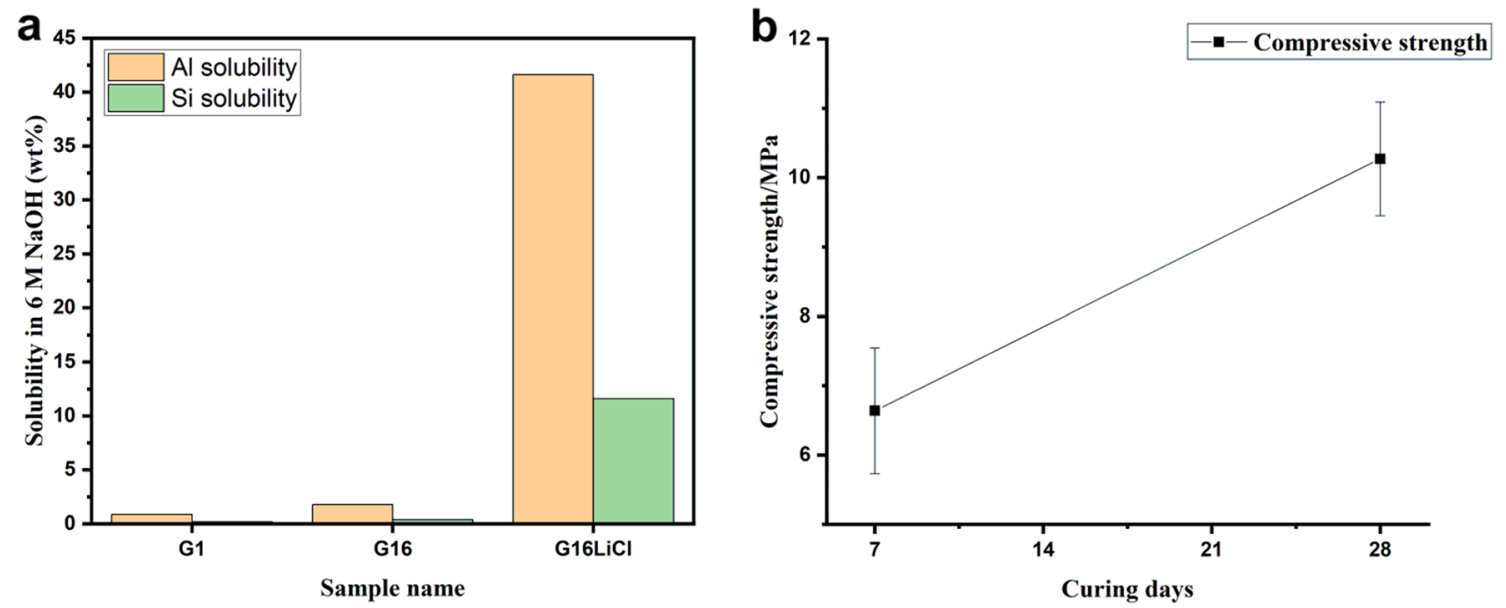

Fig. $10 \mathbf{a ~ A l}$ and Si solubility of ground samples and $\mathbf{b}$ compressive strength of IPG16LiCl

structure without a uniform elemental distribution and clear grain boundary.

Waste rock-based alkali-activated materials were prepared, and the compressive strength was measured on days 7 and 28. IPG16LiCl28 displays a moderate 28-day compressive strength of $10.3 \mathrm{MPa}$ (Fig. 10b). Furthermore, it meets the minimum requirement of compressive strength for bricks under negligible weathering conditions according to ASTM 
C62-99 [40]. The inert minerals, such as quartz and pyrite, fill in the matrix as fine aggregates. Although $40 \% \mathrm{Al}$ solubility is reached, the initial amount of $\mathrm{Al}$ is rather low (13 wt\%), which results in a moderate compressive strength in this case. It should be mentioned that the sample IPG16 was prepared with untreated waste rock. However, the sample did not harden when cured at room temperature and maintained its slurry form at day 28 . Moreover, oxidized pyrite transforms to mobilized sulfate, increasing the possibility of acid leaching, which requires a further leaching assessment of the resultant geopolymer.

\section{SEM and EDS of Waste Rock-Based Geopolymer}

The 28-day sample was subjected to an SEM analysis. The dense matrix may be correlated with an N-A-S-H-type gel (area 2 in Fig. 11). The term geopolymer will be used to refer to the N-A-S-H gel in this study, while the waste rockbased geopolymer represents the complex combination of geopolymer and inert fine aggregates such as pyrite, quartz, and unreacted mica. Area 1 of the ternary diagram shows quartz and aluminosilicates, since not all aluminosilicates can be transformed into an amorphous phase after mechanochemical activation. The dissolved $\mathrm{Al}$ species can react with silicate species from both dissolved $\mathrm{Si}$ and sodium silicate solution to form N-A-S-H gel, as displayed in the ternary

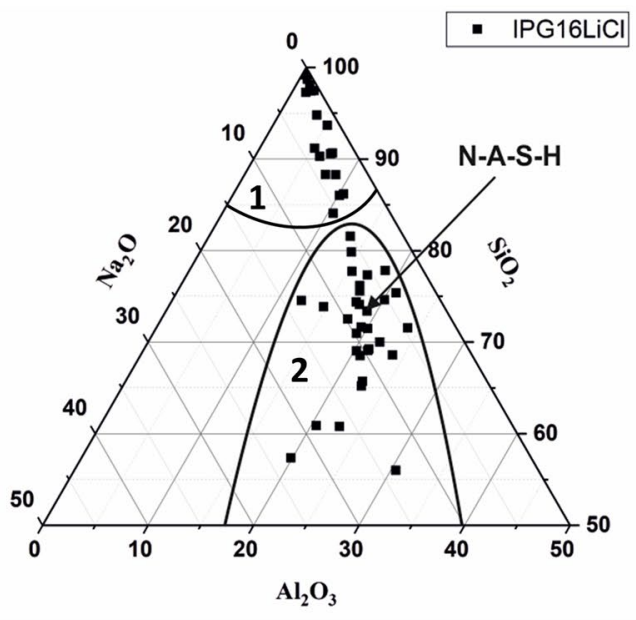

Si $K \alpha 1$
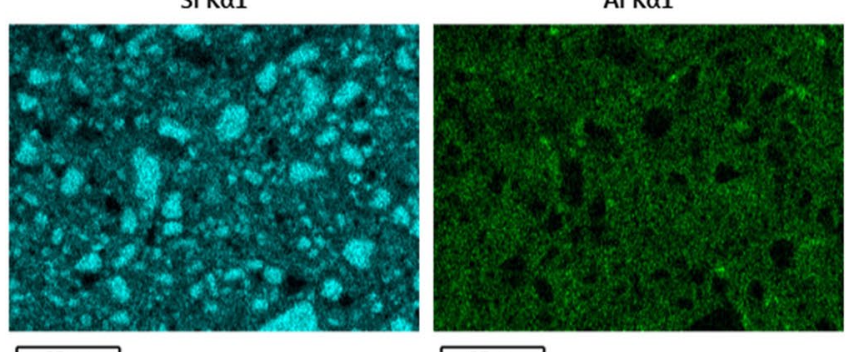

$\longdiv { 2 5 \mu \mathrm { m } }$ diagram. It is important to note that the $\mathrm{Na} / \mathrm{Al}$ ratio was held constant at 1:1 to achieve the overall charging balance of the resulting geopolymer. The Si mapping indicates the highly crystalline silica, and the black dots are attributed to inert pyrite crystals. Al mapping shows the distribution of geopolymeric gel since $\mathrm{Al}$ is dissolved from the amorphous phase. This result is in line with the alkaline solubility test where a large proportion of aluminum dissolves in the presence of an alkali solution. The dissolved aluminate species can react with silicate species in the subsequent condensation, where most of the silicate units come from the sodium silicate solution. Therefore, the condensation was dominated by the reaction between aluminate and silicate which are mostly oligomeric [41]. The ternary diagram indicates the formation of the N-A-S-H gel combined with unreacted aluminosilicates, in which the formation of N-A-S-H gel involves the dissolution of aluminosilicates and geopolymerization, i.e., precipitating and polymerizing to a threedimensional framework.

\section{Simulation of Grinding Process and Life-Cycle Assessment}

Figure 12 shows the compilation of results specifically for global warming potential and water depletion. The results for other categories are depicted in Table 4. An industrial-scale

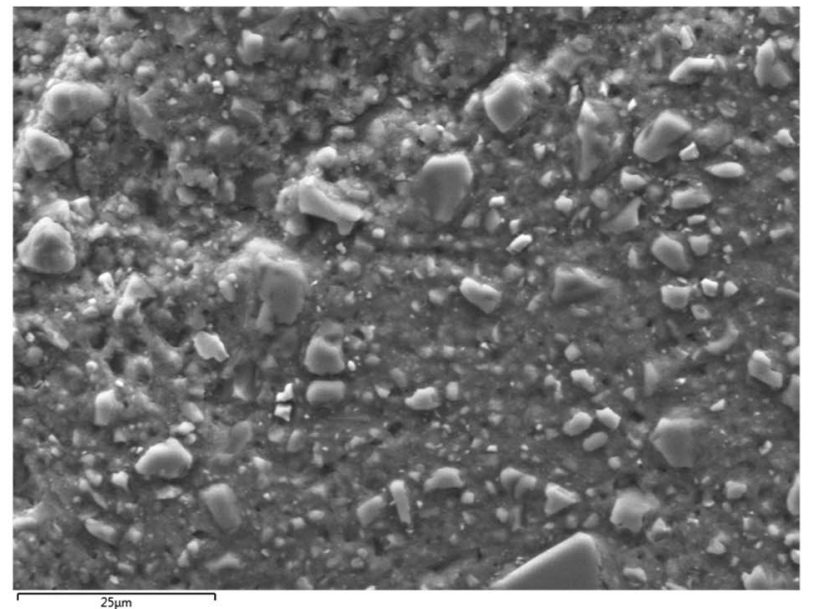

Na K $\alpha 1 \_2$

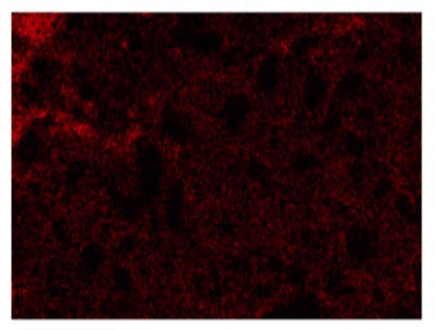

$25 \mu \mathrm{m}$

Mg Ka1_2

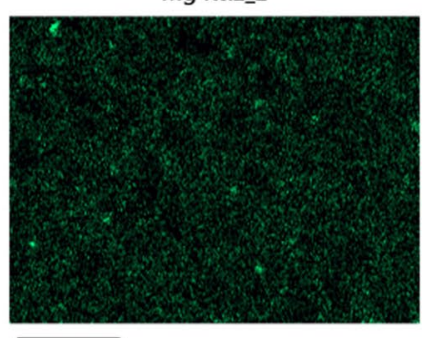

$25 \mu \mathrm{m}$

Fig. 11 SEM-EDS analysis of 28-day IPG16LiCl 

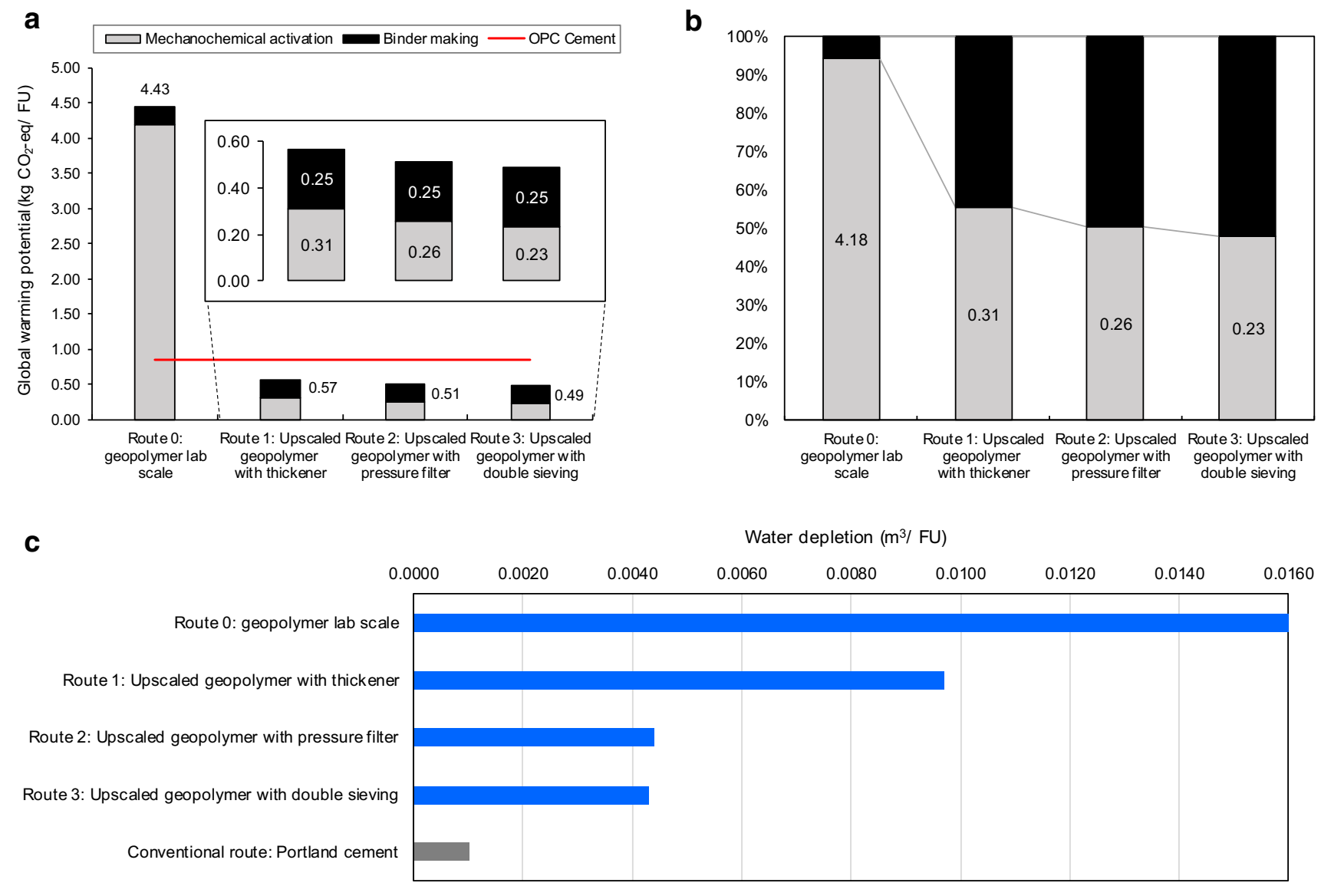

Water depletion $\left(\mathrm{m}^{3} / \mathrm{FU}\right)$

Fig. 12 The global warming potential of geopolymer binder production $\mathbf{a}$ and the share of impacts $\mathbf{b}$. Part $\mathbf{c}$ compares the water depletion to produce the same output with different configurations

Table 4 The environmental impacts of supplying $1 \mathrm{~kg}$ binder material across different impact assessment methods

\begin{tabular}{|c|c|c|c|c|c|c|c|}
\hline $\begin{array}{l}\text { Process option to } \\
\text { produce } 1 \mathrm{~kg} \text { binder }\end{array}$ & $\begin{array}{l}\text { IPCC } \\
2013 \text {, in } \\
\mathrm{CO}_{2} \text {-eq }\end{array}$ & $\begin{array}{l}\text { CED non- } \\
\text { renewable, fossil } \\
\text { in MJ }\end{array}$ & $\begin{array}{l}\text { ReCipe water } \\
\text { depletion, in } \\
\mathrm{m}^{3}\end{array}$ & $\begin{array}{l}\text { ReCipe particulate } \\
\text { matter formation, in } \\
\text { kg PM10-eq }\end{array}$ & $\begin{array}{l}\text { CML acidifi- } \\
\text { cation, in kg } \\
\mathrm{SO}_{2} \text {-eq }\end{array}$ & $\begin{array}{l}\text { CML resource } \\
\text { depletion, in kg } \\
\text { Sb-eq }\end{array}$ & $\begin{array}{l}\text { ReCipe } \\
\text { endpoint, } \\
\text { in } \mathrm{Pt}\end{array}$ \\
\hline $\begin{array}{l}\text { Route 0: geopolymer } \\
\text { lab scale }\end{array}$ & 4.43 & 52.62 & $2.8 \mathrm{E}-02$ & $7.5 \mathrm{E}-03$ & $3.1 \mathrm{E}-02$ & $2.1 \mathrm{E}-02$ & 0.469 \\
\hline $\begin{array}{l}\text { Route 1: upscaled } \\
\text { geopolymer with } \\
\text { thickener }\end{array}$ & 0.57 & 5.88 & $9.7 \mathrm{E}-03$ & $1.1 \mathrm{E}-03$ & $3.4 \mathrm{E}-03$ & $3.1 \mathrm{E}-03$ & 0.063 \\
\hline $\begin{array}{l}\text { Route 2: upscaled } \\
\text { geopolymer with } \\
\text { pressure filter }\end{array}$ & 0.51 & 5.26 & $4.4 \mathrm{E}-03$ & $1.0 \mathrm{E}-03$ & $3.1 \mathrm{E}-03$ & $2.8 \mathrm{E}-03$ & 0.057 \\
\hline $\begin{array}{l}\text { Route 3: upscaled } \\
\text { geopolymer with } \\
\text { double sieving }\end{array}$ & 0.49 & 5.01 & $4.3 \mathrm{E}-03$ & $9.7 \mathrm{E}-04$ & $2.9 \mathrm{E}-03$ & $2.7 \mathrm{E}-03$ & 0.054 \\
\hline $\begin{array}{l}\text { Conventional route: } \\
\text { Portland cement }\end{array}$ & 0.86 & 3.03 & $1.0 \mathrm{E}-03$ & $1.0 \mathrm{E}-03$ & $1.7 \mathrm{E}-03$ & $1.7 \mathrm{E}-03$ & 0.053 \\
\hline $\begin{array}{l}\text { The optimum (Route } \\
\text { 3) compared to } \\
\text { Portland cement }\end{array}$ & $-43 \%$ & $65 \%$ & $319 \%$ & $-6 \%$ & $75 \%$ & $59 \%$ & $2 \%$ \\
\hline
\end{tabular}


flowsheet grinding process simulation was conducted, and this was modeled in line with the laboratory-scale experimental data [42]. Drastic reductions of more than $90 \%$ are expected from the upscaling of geopolymer (route 0 to the respective three large-scale configurations). The conversion of equipment from pulverizers to a set of crushing and milling equipment manages to minimize the amount of electricity needed, decreasing energy consumption in the first step of the process, i.e., mechanochemical activation. Similar to the modeling of other lab-scale technologies, greenhouse gas emissions also decrease due to scaling effects of electricity consumption [43, 44]. Finally, when compared to the production of ordinary Portland cement, all geopolymer production routes can compete with the average $40 \%$ global warming potential (GWP) reduction potentials, except for the lab-scale scenario (Fig. 12a). It is important to note that with geopolymer routes, one can eliminate the calcination process that contributes to most of the emissions in the making of Portland cement. Once the system reaches common industrial throughput (i.e., $100 \mathrm{ton} / \mathrm{h}$ ), the contribution towards GWP is almost equally shared between precursor production and geopolymer binder manufacturing (Fig. 12b).

Nevertheless, when it comes to the six other impact categories, the results are different (Table 4), barring particular matter formation. Although the second and third routes can minimize the water consumption in the grinding circuit (Table 5), the consumption is still higher in all scenarios compared to the production of Portland cement. The other two impact categories also reflect similar trends. The use of lithium chloride as a grinding aid as well as alkali activators (e.g., sodium hydroxide and sodium silicate solution) results in higher resource consumption from the production of such chemicals. One can mitigate these issues by sourcing alkalis from underutilized waste to avoid the need for primary alkali productions in the system [45]. The other cause is due to the definition of the functional unit for this study. With the relatively low mechanical performance of geopolymer developed in our study, the environmental impacts are amplified to almost four times that of OPC. Therefore, even though this specific mine waste and recipe cannot be sustainably scaled

Table 5 Summary of LCA indicators for each mode

\begin{tabular}{lllll}
\hline Model type & \multicolumn{4}{l}{$\begin{array}{l}\text { LCA indicators (For production of precursor 1 kg) } \\
\text { The summarized data in this table are taken from simu- } \\
\text { lation results in Supplementary Figs. S2-S4 }\end{array}$} \\
\cline { 2 - 5 } & $\begin{array}{l}\text { Precursor } \\
\text { products } \\
(\mathrm{kg})\end{array}$ & $\begin{array}{l}\text { Water } \\
\text { recovery } \\
(\mathrm{kg})\end{array}$ & $\begin{array}{l}\text { Fresh water } \\
\text { consumption } \\
(\mathrm{kg})\end{array}$ & $\begin{array}{l}\text { Electric- } \\
\text { ity }(\mathrm{kWh} \\
\left.10^{-3}\right)\end{array}$ \\
\hline Route 1 & 1 & 0.00 & 1.17 & 25.06 \\
Route 2 & 1 & 0.72 & 0.16 & 21.36 \\
Route 3 & 1 & 0.68 & 0.15 & 20.76 \\
\hline
\end{tabular}

up, this amount of mechanochemical treatment and chemical use may be justified, given that an adequate mechanical strength is reached. As this system has not been optimized, this result is expected. The mechanical strength can be increased via further optimization and by extending the assessment boundary until the production of concrete or mor$\operatorname{tar}$ [46]. With such a methodological choice, the mechanical strength in the geopolymer pathways will increase, and the sustainability benefits can also be better justified. Thus, the study also implies the following promising avenues for further investigations: (i) using the developed geopolymer binders to produce concrete/mortars, (ii) formulating new recipes for alkali activating geopolymers, and (iii) a combination of both strategies. With the right alkali formulations and mix designs [47], the developed geopolymer concrete can compete with standard cement concrete from an environmental perspective. Lithium-containing grinding aid is suitable for lab-scale production; however, it can be critical when upscaling the valorization of millions of tons of waste rock. From the perspective of a circular economy, the recycling of lithium from the battery industry or the seeking of an alternative cheap grinding aid for an industrial application can be the subject of future endeavors.

\section{Conclusion}

In summary, this study indicates that sulfidic mining waste rock can be a potential candidate for the fabrication of geopolymers after mechanochemical activation. Lithium chloride grinding aids can significantly improve the amorphization of the waste rock during grinding, thereby enhancing $\mathrm{Si}$ and $\mathrm{Al}$ dissolution. In contrast, ground waste rock with typical grinding aid (e.g., isopropanol) retains the waste rock's crystalline structure. This coincides with the generation of an amorphous phase in which chemically assisted mechanochemically activated samples possess more amorphous phases than mechanochemically treated samples regardless of grinding time. The amorphous aluminosilicates (e.g., muscovite, clinochlore) resulting from structural distortion/dislocation were obtained after mechanochemical treatment in terms shown by the XRD and TEM analyses. The optimal unconfined compressive strength for geopolymer produced from 16-min grinding waste rock with $\mathrm{LiCl}(\mathrm{G} 16 \mathrm{LiCl})$ is $10.27 \mathrm{MPa}$ after 28 days of curing under ambient conditions. Despite the complexity of mineralogy, a proper pre-treatment method should be considered before designing the activation route. It should be noted that similar mineralogy (e.g., aluminosilicate-bearing clay resources) can express different stoichiometry compositions and degrees of crystallinity due to mineralization, weathering, and crust conditions (geological origin).

Simulation can be a versatile tool when upscaling lab work to an industrial scale, as it offers a vital method for 
minimizing costs and predicting the results. When life-cycle assessment is implemented, the environmental impact of the simulated process can pinpoint the advantages and disadvantages of several design choices. Indeed, the environmental performance of geopolymer production increases drastically due to optical energy minimization, a result that is parallel to the continuous proposal of sustainable alkali activators and mix strategies in geopolymer production.

Supplementary Information The online version contains supplementary material available at https://doi.org/10.1007/s40831-021-00466-9.

Acknowledgements This research was funded by the European Union's Framework Program for Research and Innovation Horizon 2020 under Grant Agreement No. 812580, Project "MSCA-ETN SULTAN." We thank Dr. Fedor Vasilyev from Metso Outotec for the valuable suggestion of HSC chemistry simulation, Prof. Antti Häkkinen from Lappeenranta University of Technology for supplying laboratory equipment, Toni Väkiparta for the QXRD analysis, Stephan Pfister from ETH Zurich for discussions on life-cycle assessment methodology, and Mafalda Oliveira from SOMINCOR by Lundin Mining for providing the waste rock samples and information. The authors would like to thank Marcin Selent for his help with XRD analysis, Pasi Juntunen for the FESEM measurement, Sami Saukko for TEM, and Nan Ding for depicting the graphical abstract. We thank Mr. Jarno Karvonen, Mr. Jani Österlund, and Mrs. Elisa Wirkkala for their contribution to laboratory work. Part of the work was carried out with the support of the Centre for Material Analysis, University of Oulu, Finland. P.P. gratefully acknowledges the financial support received from the Academy of Finland [GEOMINS Grant \# 319676], and P. K. is grateful for the support from the University of Oulu and The Academy of Finland \#326291.

Funding Open Access funding provided by University of Oulu including Oulu University Hospital.

\section{Declarations}

Conflict of interest The authors declare that they have no conflict of interest.

Open Access This article is licensed under a Creative Commons Attribution 4.0 International License, which permits use, sharing, adaptation, distribution and reproduction in any medium or format, as long as you give appropriate credit to the original author(s) and the source, provide a link to the Creative Commons licence, and indicate if changes were made. The images or other third party material in this article are included in the article's Creative Commons licence, unless indicated otherwise in a credit line to the material. If material is not included in the article's Creative Commons licence and your intended use is not permitted by statutory regulation or exceeds the permitted use, you will need to obtain permission directly from the copyright holder. To view a copy of this licence, visit http://creativecommons.org/licenses/by/4.0/.

\section{References}

1. Eurostat (2018) Waste statistics (2018). https://ec.europa.eu/euros tat/statistics-explained/index.php/Waste_statistics\#Total_waste_ generation. Accessed 27 Nov 2020
2. Bian Z, Miao X, Lei S et al (2012) The challenges of reusing mining and mineral-processing wastes. Science 337:702-703. https:// doi.org/10.1126/science.1224757

3. Bhatty JI, Marijnissen J, Reid KJ (1985) Portland cement production using mineral wastes. Cem Concr Res 15:501-510. https:// doi.org/10.1016/0008-8846(85)90124-3

4. Glukhovsky V (1959) Soil silicates (Gruntosilikaty). Budivelnik Publisher, Kiev

5. Davidovits J (1991) Geopolymers: inorganic polymeric new materials. J Therm Anal Calorim 37:1633-1656

6. Pacheco-Torgal F, Castro-Gomes J, Jalali S (2007) Investigations about the effect of aggregates on strength and microstructure of geopolymeric mine waste mud binders. Cem Concr Res 37:933941. https://doi.org/10.1016/j.cemconres.2007.02.006

7. Tole I, Habermehl-Cwirzen K, Rajczakowska M, Cwirzen A (2018) Activation of a raw clay by mechanochemical processeffects of various parameters on the process efficiency and cementitious properties. Materials 11:1860

8. Andersson-Sköld Y, Torrance JK, Lind B et al (2005) Quick clay-a case study of chemical perspective in Southwest Sweden. Eng Geol 82:107-118. https://doi.org/10.1016/j.enggeo.2005.09. 014

9. Moukannaa S, Nazari A, Bagheri A et al (2019) Alkaline fused phosphate mine tailings for geopolymer mortar synthesis: thermal stability, mechanical and microstructural properties. J Non-Cryst Solids 511:76-85. https://doi.org/10.1016/j.jnoncrysol.2018.12. 031

10. Yao G, Zang H, Wang J et al (2019) Effect of mechanical activation on the pozzolanic activity of muscovite. Clays Clay Miner 67:209-216. https://doi.org/10.1007/s42860-019-00019-y

11. Papirer E, Eckhardt A, Muller F, Yvon J (1990) Grinding of muscovite: influence of the grinding medium. J Mater Sci 25:51095117. https://doi.org/10.1007/BF00580138

12. Ikazaki F, Uchida K, Kamiya K et al (1996) Chemically assisted dry comminution of sericite-dry comminution method accompanied by ion-exchange. Int J Miner Process 44-45:93-100. https:// doi.org/10.1016/0301-7516(95)00021-6

13. Roine A (2018) HSC Chemistry software. Outotec, Pori Software. https://www.mogroup.com/portfolio/hsc-chemistry/?r=2. Accessed 27 Nov 2020

14. Abadías Llamas A, Valero Delgado A, Valero Capilla A et al (2019) Simulation-based exergy, thermo-economic and environmental footprint analysis of primary copper production. Miner Eng 131:51-65. https://doi.org/10.1016/J.MINENG.2018.11.007

15. Ruuska J, Lamberg P, Leiviskä K (2012) Flotation model based on floatability component approach-PGE minerals case. IFAC Proc Vol 45:19-24

16. Korolev I, Remes A, Stoilov V, et al (2018) HSC Sim® simulation model of the Assarel copper flotation circuit based on process mineralogy and metallurgical testing

17. Lishchuk V, Lund C, Lamberg P, Miroshnikova E (2018) Simulation of a mining value chain with a synthetic ore body model: iron ore example. Minerals 8:536. https://doi.org/10.3390/min8110536

18. Roine T, Kaartinen J, Lamberg P (2011) Training simulator for flotation process operators. IFAC Proc Vol 44:12138-12143

19. Relvas J (2002) The Neves-Corvo deposit, Iberian pyrite belt, Portugal: impacts and future, 25 years after the discovery. In integrated methods for discovery: global exploration in the twentyfirst century. Econ Geol Special Publ 9:155-176

20. Lundin Mining (2019) Mineral resources and reserves. https:// www.lundinmining.com/operations/neves-corvo/. Accessed 1 June 2020

21. Escobar AG, Relvas JMRS, Pinto ÁMM, Oliveira M (2021) Physical-chemical characterization of the Neves Corvo extractive mine residues: a perspective towards future mining and reprocessing 
of sulfidic tailings. J Sustain Metall. https://doi.org/10.1007/ s40831-021-00428-1

22. Li C, Cui S, Nie Z et al (2015) The LCA of portland cement production in China. Int J Life Cycle Assess 20:117-127. https://doi. org/10.1007/s11367-014-0804-4

23. Panesar DK, Seto KE, Churchill CJ (2017) Impact of the selection of functional unit on the life cycle assessment of green concrete. Int J Life Cycle Assess 22:1969-1986. https://doi.org/10.1007/ s11367-017-1284-0

24. Guinee JB (2002) Handbook on life cycle assessment operational guide to the ISO standards. Int J Life Cycle Assess 7:311. https:// doi.org/10.1007/BF02978897

25. Outotec (2020) HSC chemistry. https://www.mogroup.com/portf olio/hsc-chemistry/?r=2. Accessed 5 Jun 2020

26. Coleman R, Lamberg P (2010) Flotation circuit optimisation using modelling and simulation software. Outotec Australia's quarterly e-newsletter

27. Steubing B, de Koning D, Haas A, Mutel CL (2020) The activity browser-an open source LCA software building on top of the brightway framework. Softw Impacts 3:100012. https://doi.org/ 10.1016/j.simpa.2019.100012

28. Wernet G, Bauer C, Steubing B et al (2016) The ecoinvent database version 3 (part I): overview and methodology. Int J Life Cycle Assess 21:1218-1230. https://doi.org/10.1007/s11367-016-1087-8

29. Bailey SW (2018) Micas. Walter de Gruyter GmbH \& Co KG, Berlin

30. Villieras F (1994) Development of microporosity in clinochlore upon heating. Clays Clay Miner 42:679-688. https://doi.org/10. 1346/CCMN.1994.0420604

31. Che C, Glotch TD, Bish DL et al (2011) Spectroscopic study of the dehydration and/or dehydroxylation of phyllosilicate and zeolite minerals. J Geophys Res 116:E05007. https://doi.org/10. 1029/2010JE003740

32. Perumal P, Niu H, Kiventerä J et al (2020) Upcycling of mechanically treated silicate mine tailings as alkali activated binders. Miner Eng 158:106587

33. Schroeder PA (2002) Infrared spectroscopy in clay science. The Clay Mineral Society, Aurora, pp 181-206

34. Devineau K, Villiéras F, Barrès O (2007) Development and evolution of water vapor vesicles during fast thermal breakdown of muscovite. Phys Chem Miner 34:559-572. https://doi.org/10. 1007/s00269-007-0171-9

35. Vedder W, Wilkins RWT (1969) Dehydroxylation and rehydroxylation, oxidation and reduction of micas. Am Miner 54:482-509
36. McKeown DA, Bell MI, Etz ES (1999) Vibrational analysis of the dioctahedral mica; $2 \mathrm{M}_{1}$ muscovite. Am Miner 84:1041-1048. https://doi.org/10.2138/am-1999-7-806

37. White JL, Bailey GW, Brown CB, Alrichs JL (1961) Infra-red investigation of the migration of lithium ions into empty octahedral sites in muscovite and montmorillonite. Nature 190:342-342. https://doi.org/10.1038/190342a0

38. Bell IA, Wilson CJL (1981) Deformation of biotite and muscovite: tem microstructure and deformation model. Tectonophysics 78:201-228. https://doi.org/10.1016/0040-1951(81)90014-7

39. Niu H, Kinnunen $P$, Sreenivasan $\mathrm{H}$ et al (2020) Structural collapse in phlogopite mica-rich mine tailings induced by mechanochemical treatment and implications to alkali activation potential. Miner Eng 151:106331. https://doi.org/10.1016/j.mineng.2020.106331

40. ASTM C67/C67M-20 (2020) Standard test methods for sampling and testing brick and structural clay tile. ASTM International, West Conshohocken

41. Sagoe-Crentsil K, Weng L (2007) Dissolution processes, hydrolysis and condensation reactions during geopolymer synthesis: part II. High Si/Al ratio systems. J Mater Sci 42:3007-3014. https:// doi.org/10.1007/s10853-006-0818-9

42. Adrianto LR, Niu H, Pfister S (2021) LIfe cycle assessment of emerging processes to valorize mining waste

43. Gavankar S, Suh S, Keller AA (2015) The role of scale and technology maturity in life cycle assessment of emerging technologies: a case study on carbon nanotubes. J Ind Ecol 19:51-60

44. Kawajiri K, Goto T, Sakurai S et al (2020) Development of life cycle assessment of an emerging technology at research and development stage: a case study on single-wall carbon nanotube produced by super growth method. J Clean Prod 255:120015

45. Adesanya E, Perumal P, Luukkonen T et al (2020) Opportunities to improve sustainability of alkali activated materials: review of side-stream based activators. J Clean Prod 286:125558

46. Ouellet-Plamondon C, Habert G (2015) Life cycle assessment (LCA) of alkali-activated cements and concretes. In: PachecoTorgal F, Labrincha JA, Leonelli C, Palomo A, Chindaprasirt P (eds) Handbook of alkali-activated cements, mortars and concretes. Elsevier, Boston, pp 663-686

47. Hassan A, Arif M, Shariq M (2019) Use of geopolymer concrete for a cleaner and sustainable environment - a review of mechanical properties and microstructure. J Clean Prod 223:704-728

Publisher's Note Springer Nature remains neutral with regard to jurisdictional claims in published maps and institutional affiliations.

\section{Authors and Affiliations}

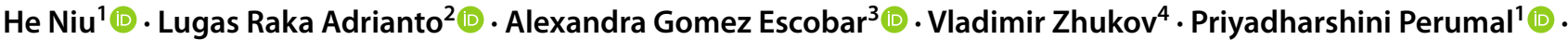 Janne Kauppi ${ }^{4} \cdot$ Paivo Kinnunen $^{1}{ }^{1} \cdot$ Mirja Illikainen $^{1}{ }^{[}$}

\section{Mirja Illikainen}

Mirja.Illikainen@oulu.fi

1 Fiber and Particle Engineering Research Unit, University of Oulu, P.O. Box 4300, 90570 Oulu, Finland

2 Chair of Ecological Systems Design, Institute for Environmental Engineering, ETH Zurich, John-von-Neumann-Weg 9, 8093 Zurich, Switzerland
3 Faculdade de Ciências, Instituto Dom Luiz, Universidade de Lisboa, Edifício C6, Piso 4, Campo Grande, 1749-016 Lisbon, Portugal

4 Metso Outotec Finland Oy, Tukkikatu 1, P.O. Box 29, 53101 Lappeenranta, Finland 